\title{
Assessment of derived sunflower oil as environmentally friendly plasticizers in Poly Vinyl Chloride
}

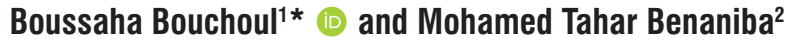 \\ ${ }^{1}$ Research Center in Industrial Technologies CRTI, P.0. Box 64 Cheraga 16014, Algiers, Algeria \\ ${ }^{2}$ Laboratory of Multiphase Polymeric Materials (LMPMP), Faculty of Technology, Setif-1 University, \\ 19000 Setif, Algeria \\ *b.bouchoul@crti.dz; b_bouchoul@yahoo.com
}

\begin{abstract}
Epoxidized sunflower oil (ESO) and epoxidized sunflower oil methyl ester (ESOME) were synthetized and employed as secondary bio based plasticizers and combined with primary natural plasticizers. As such, di-esters isosorbide (DEI) and acetyl tributyl citrate (ATBC) used in Poly Vinyl Chloride (PVC) as compared to di-(2-ethylhexyl) phthalate (DEHP). PVC Sheets were obtained by processed the polymer and its additives on two-roll mill. The effect of the plasticizers combination on flexible sheets properties, including stabilization, migration, fusion rheological properties and light transmission have been discussed, Results have shown that ESO and ESOME have improved PVC formulations thermal stability, the weight loss by volatility has decreased in the formulations which contained ESO or ESOME. Mixtures of plasticizers have lower migration rates. Plastograph test has indicated a better compatibility of PVC with these plasticizer mixtures. The light transmission rate through PVC sheets plasticized by bio-based plasticizers mixtures is more than those containing DEHP.
\end{abstract}

Keywords: biobased plasticizers, migration, PVC, plasticizers combinations, sunflower oil.

How to cite: Bouchoul, B., \& Benaniba, M. T. (2021). Assessment of derived sunflower oil as environmentally friendly plasticizers in Poly Vinyl Chloride. Polimeros: Ciência e Tecnologia, 31(3), e2021025. https://doi.org/10.1590/01041428.20210015

\section{Introduction}

Polyvinyl chloride (PVC) has a wide range of applications in various fields that have several advantages such as product performance, material processing capability, thermal stability, relatively low cost and versatility. Generally, it has been used with various additives such as thermal stabilizers, plasticizers, lubricants, fillers ...etc, according to the application or depending on desired properties ${ }^{[1,2]}$. Plasticizers are the most consumable additives in $\mathrm{PVC}^{[3]}$. These materials are mainly used to modify the polymer chain flexibility, the glass transition temperature (Tg), degree of crystallinity, optical transparency and Young modulus ${ }^{[3-5]}$. The most widely used PVC plasticizer in the world is di(2-ethylhexyl) phthalate (DEHP) as a primary plasticizer. Plasticizers based on phthalates account for more than $90 \%$ of the total plasticizers used in PVC which DEHP represents more than $50 \%$ of the total phthalates ${ }^{[6-9]}$. Unfortunately, this phthalates migrate easily from PVC formulations and reduce the performance of PVC products with time ${ }^{[10]}$. Yet, petroleum-based plasticizers reveal negative environmental and health effects ${ }^{[11-13]}$. They would result in possible toxicity and high danger to contaminate environment and human food, as they are also suspected of having carcinogenic effects ${ }^{[1,5,14]}$. These have led researchers ${ }^{[15-19]}$ to be interested in substituting these polluting substances with bio-based products that have no negative impact on the environment or

on human health ${ }^{[11]}$ by using some derivatives of vegetable oils, such as, soybean oil, linseed oil and sunflower oil, and to make these vegetable oils compatible with PVC, they have subjected to an epoxidation reaction where an oxygen atom introduced into the doubles bonds of carbon chains of fatty acids forming an oxirane ring, where the resulting properties are dependent on the epoxidation level which is linked with the iodine number ${ }^{[20]}$. Epoxidized soybean oil has been widely used in PVC as a secondary plasticizer, but it shows partial compatibility with PVC compared to petroleum based plasticizers ${ }^{[21]}$. But with its esterification by an alcohol improves the plasticizing effect on PVC and the resistance to migration against DEHP ${ }^{[22]}$.

For this, we use sunflower oil, which has a high content of non-conjugated double bonds that are simply epoxidized by oxygen peroxide to produce epoxidized sunflower oil (ESO), and it shows a plasticizing effect higher than that of epoxidized soybean oil (ESBO $)^{[23]}$. Then ESO is esterified by methanol to obtain epoxidized sunflower oil methyl ester (ESOME) ${ }^{[17]}$. These are used as secondary plasticizers to improve the thermal stability of PVC and increase the compatibility ${ }^{[24]}$. The use of a plasticizer alone does not satisfy all the desired performances; therefore, it is possible to use a combination of plasticizers in order to meet more properties of the PVC according to a particular application. 
The present study evaluates the performance of biobased plasticizers combinations in polyvinyl chloride (PVC). The secondary natural plasticizers were synthesized in our laboratory by epoxidation reaction of sunflower oil and esterification of epoxidized sunflower oil; these products were combined with primary bio-based plasticizers which are di-ester isosorbide (DEI) and acetyl tributyl citrate (ATBC).The formulations are prepared by mixing plasticizers combination and other additives with PVC resin which one contained DEHP alone used as reference. Then, blends aremixed and heated; sheets of plasticized PVC are obtained. Several techniques such as thermogravimetric analysis (TGA) in isothermal mode, volatility and migration tests, internal mixer test and light transmission have been used to study the thermal, physicochemical and rheological properties in order to search for a synergism of properties between these combinations of plasticizers.

\section{Materials and Methods}

Polyvinyl chloride (PVC), suspension grade resin (SE 950, K 65.7-67.1), was kindly supplied by SHINTECH (Houston, USA). Plasticizers used were as follows: Acetyl tributyl citrate (ATBC) from Sigma Aldrich, USA, Diesters isosorbide(DEI), ID47 from Roquette Frères, France, Epoxidized sunflower oil (ESO) and Epoxidized sunflower oil methyl ester (ESOME) with $6.1 \%$ of oxirane oxygen index, were prepared in our laboratory and have been reported in our previous study ${ }^{[17]}$, Di-(2-ethylhexyl) phthalate (DEHP) as plasticizer reference was supply from Plastimed, Tunisia.

\subsection{PVC sheets preparation}

The preparation of the PVC with plasticizers mixtures was carried out in a two-roll mill of the Rodolfo Comero type. It is a method of mixing the melt material by crushing between two heated and mechanically driven rolls. Blends were obtained by manually mixing the PVC resin and additives (plasticizers, stabilizers and lubricants), and then they were placed in the mixer at $160^{\circ} \mathrm{C}$ for 10 minutes until the resin was completely homogenized.

\subsection{Formulations}

Table 1 presents the various formulations in which the additive contents were kept constant:

- $100 \mathrm{phr}$ of the PVC resin;

- $1 \mathrm{phr}$ for the lubricant which is stearic acid (SA);

- 2 phr for the thermal stabilizer which is Calcium / Zinc stearates;

Table 1. Plasticizer systems compositions.

\begin{tabular}{ccccccccc}
\hline \multirow{2}{*}{ Plasticizers (\%) } & \multicolumn{8}{c}{ Formulation Number } \\
\cline { 2 - 10 } & $\mathbf{0}$ & $\mathbf{1}$ & $\mathbf{2}$ & $\mathbf{3}$ & $\mathbf{4}$ & $\mathbf{5}$ & $\mathbf{6}$ & $\mathbf{7}$ \\
\hline DEI & - & 100 & 50 & 00 & 50 & - & 50 & - \\
ATBC & - & 00 & 50 & 100 & - & 50 & - & 50 \\
ESO & - & - & - & - & 50 & 50 & - & - \\
ESOME & - & - & - & - & - & - & 50 & 50 \\
DEHP & 100 & - & - & - & - & - & - & - \\
\hline
\end{tabular}

- $60 \mathrm{phr}$ for the plasticizer system containing DEI, ATBC, ESO and/or ESOME;

The various plasticized formulations are obtained either in the presence of plasticizer alone, DEI or ATBC or with their binary combinations with ESO and ESOME, in addition to a reference formulation which contains DEHP alone as plasticizer.

\subsection{Thermal gravimetric analysis (TGA)}

TGA was performed using a TA Instruments (TGA Q500, USA). Isothermal weight loss studies were conducted at $160{ }^{\circ} \mathrm{C}, 180^{\circ} \mathrm{C}$ and $200^{\circ} \mathrm{C}$ for 90 minutes under $40 \mathrm{~mL} / \mathrm{min}$ of nitrogen flow. Approximately $10 \pm 2 \mathrm{mg}$ of each sample is heated from room temperature to the selected temperature with a constant heating rate of $100{ }^{\circ} \mathrm{C} / \mathrm{min}$. The mass evolutions are recorded as a function of time.

\subsection{Volatility test}

The weight loss of plasticizer from PVC sheets by volatility was determined according to ISO 176-2005. The samples $\left(25 \times 25 \mathrm{~mm}^{2}\right.$ in triplicate) are weighed and then placed in an oven at $100{ }^{\circ} \mathrm{C}$. After 24,48 and 96 hours, sheets were allowed to cool down to room temperature and are cleaned well to remove any traces of volatile plasticizers, which may condense on the sheet surfaces. The masses were measured by an analytical balance having an accuracy of $0.1 \mathrm{mg}$ and the average percentage of losses by volatility was determined.

\subsection{Migration test}

Plasticizer migration from PVC sheets was based on ASTM D1239-14 ${ }^{[25]}$. When was carried out in four different solvents (acetic acid, ethanol, petroleum ether and n-heptane) at $25^{\circ} \mathrm{C}^{[26]}$. Samples of $25 \times 25 \mathrm{~mm}^{2}$ were used in triplicate runs to confirm repeatability, were weighed and then immersed in $150 \mathrm{~mL}$ of each solvent for 48 and 96 hours, and then dried. Sheets were weighed and the average mass losses were determined.

\subsection{Plastograph test}

The plastograph is an internal mixer that tracks rotational torque as a function of time. This equipment (Brabender, Germany) allows continuously to monitoring the torque variation as a function of time. Accurately $63 \mathrm{~g}$ of the PVC and its plasticizers combinations were added into the mixer chamber at $40 \mathrm{rpm}$ and heated to $180{ }^{\circ} \mathrm{C}$ for $40 \mathrm{~min}$, a pressure is applied on the melted material by descent of a piston; the fusion rheological property was measured and recorded by Brabender ${ }^{\circledR}$ Data Correlation software.

\subsection{Light transmission}

Light transmission in PVC sheets was measured using a UV spectrophotometer (SHIMADZU UV-1800, Japan). The samples of a square shape of sizes $2.5 \times 2.5 \mathrm{~cm}^{2}$ and $0.5 \mathrm{~mm}$ thick had substantially flat-to-parallel surfaces free of dust and internal voids ${ }^{[26]}$. The results were recorded in the wavelength range 200 to $1100 \mathrm{~nm}$ at a resolution of $1 \mathrm{~nm}$. 
Transmission percentages were obtained directly from the UV Probe software.

\section{Results and Discussions}

\subsection{Thermal gravimetric analysis (TGA)}

Figure 1 shows the thermogravimetric profiles of PVC plasticized with DEI or ATBC and its mixtures with ESO or ESOME at $160^{\circ} \mathrm{C}, 180^{\circ} \mathrm{C}$ and $200^{\circ} \mathrm{C}$. PVC samples containing ESO or ESOME in their plasticizer systems show a lower weight loss after 90 minutes as compared to DEI or ATBC alone. Thus, ESO and ESOME improve the thermal stability of PVC formulations. This effect is attributed to the epoxide functions presented in the structure of secondary plasticizers ${ }^{[11]}$. It is clear that oxirane rings react with heat-generated $\mathrm{HCl}$ at a rate greater than the rate of volatilization of $\mathrm{HCl}$ from the PVC sample. The point
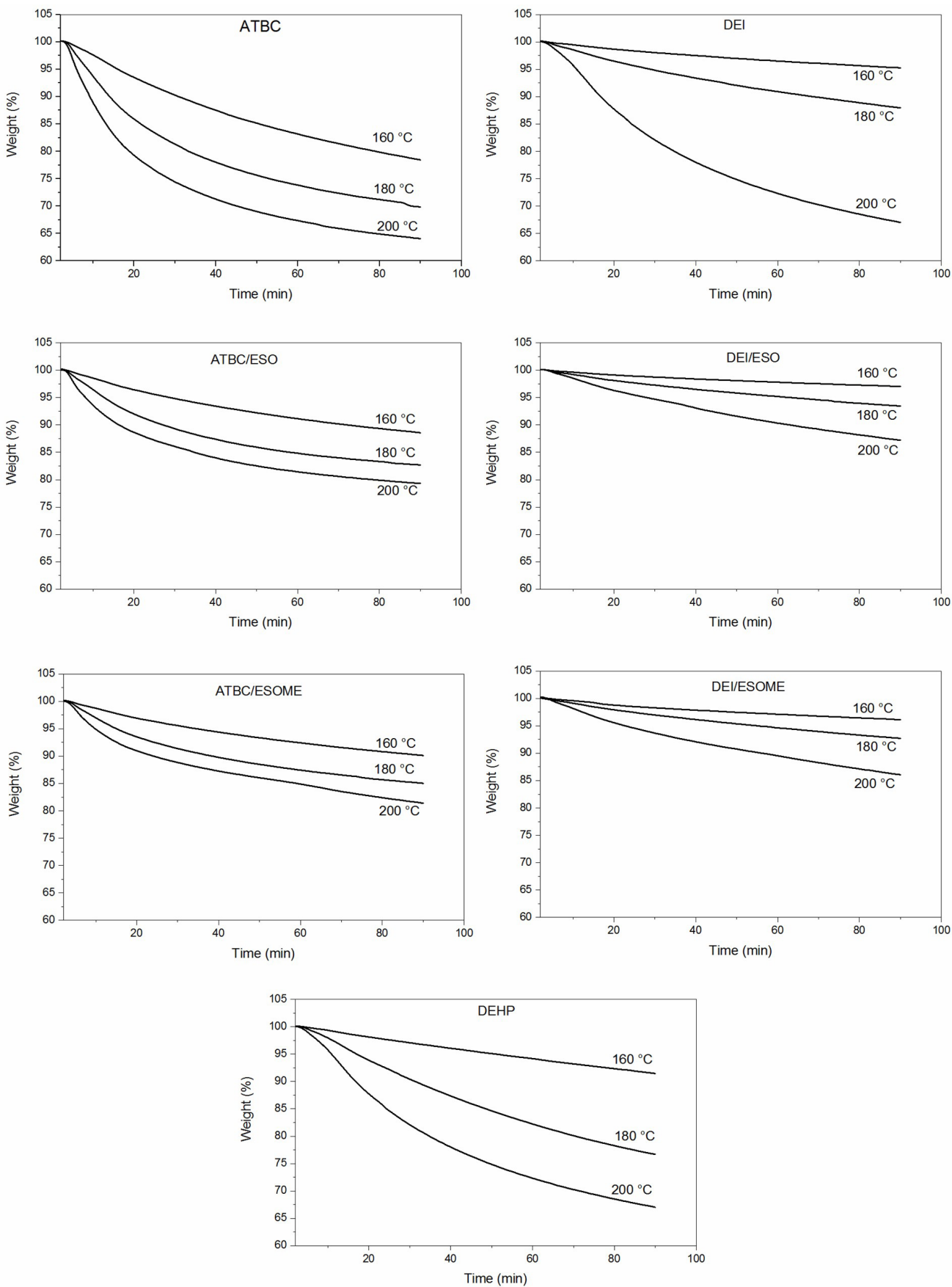

Figure 1. Weight loss by TGA in isothermal mode of PVC plasticized with DEI, ATBC and their mixtures with ESO, ESOME and with DEHP as reference. 
at which the volatilization of $\mathrm{HCl}$ dominates the reactions which cannot be determined during the 90 minutes period ${ }^{[11]}$. Therefore, maintaining the integrity of the ESO or ESOME as a secondary plasticizer is primordial because of epoxide rings and ester functions that limit the decomposition of PVC samples ${ }^{[10,27]}$.

Activation energies for the PVC degradation process were determined by TGA for PVC plasticized by DEHP and PVC with ATBC or DEI and its mixtures with ESO or ESOME according to the Arrhenius equation:

$$
k=A e^{-E a / R T}
$$

where $k$ is the degradation rate at a particular temperature, $\mathrm{A}$ is the frequency factor, $\mathrm{Ea}$ is the activation energy for the degradation process, $\mathrm{R}$ is the gas constant, and $\mathrm{T}$ is the absolute temperature.

The isothermal weight loss data of PVC plasticized with different plasticizers systems at various temperatures a long with the Arrhenius activation energy are presented in Table 2.

The plots for each sample are shown in Figure 2.

The activation energy for the initial degradation for PVC plasticized with DEHP alone is $81.79 \pm 9.63 \mathrm{~kJ}$ $\mathrm{mol}^{-1}$ while that for PVC with ATBC and DEI alone are $65.55 \pm 0.96 \mathrm{~kJ} \mathrm{~mol}^{-1}$ and $70.25 \pm 1.44 \mathrm{~kJ} . \mathrm{mol}^{-1}$, respectively. Therefore, PVC with DEHP has lost more weight than with ATBC or DEI, the activation energy has increased in the case of ATBC with ESO $\left(75.09 \pm 2.97 \mathrm{~kJ} \cdot \mathrm{mol}^{-1}\right)$ and almost remains stable with ESOME $\left(62.90 \pm 3.44 \mathrm{~kJ} \cdot \mathrm{mol}^{-1}\right)$ as compared to the plasticizer alone, but in the case of DEI, the activation energy has decreased with the incorporation of ESO $\left(44.97 \pm 9.2 \mathrm{~kJ} \cdot \mathrm{mol}^{-1}\right)$ or with the incorporation of ESOME $\left(53.79 \pm 10.89 \mathrm{~kJ}^{\mathrm{mol}}{ }^{-1}\right)$ in comparison to DEI alone. these energy reductions suggest that when PVC is plasticized with plasticizer system containing ESO and especialy ESOME that capture the $\mathrm{HCl}$ that is released by $\mathrm{PVC}$ and as such preventing the autocatalytic role of $\mathrm{HCl}$, so the weight loss is reduced, therefore the activation energy has decreased ${ }^{[11]}$. Plasticizers combination reduces migration as compared to a single plasticizer ${ }^{[28]}$.

\subsection{Volatility test}

The volatility of the plasticizers in the polymer is highly dependent on the molecular weight, solubility, compatibility, and chemical structure of the plasticizers ${ }^{[29-31]}$, and are important parameters for assessing the migration of plasticizers ${ }^{[5]}$. Figure 3 shows the mass loss by volatility. At elevated temperatures, plasticizers migrate from the PVC resin to the surface where the weight loss by volatility of the plasticizer will negatively affect the mechanical properties of the PVC films ${ }^{[26]}$.

PVC formulations contain ATBC have the highest mass loss values $(2.5 \%, 4.61 \%$ and $8.22 \%)$ over the entire test period $(24 \mathrm{~h}, 48 \mathrm{~h}$, and $96 \mathrm{~h})$ at $100{ }^{\circ} \mathrm{C}$. Meanwhile, the weight loss decreases very significantly with the integration of $\operatorname{ESO}(1.53 \%, 2.66 \%$ and $4.50 \%)$ or ESOME $(2.07 \%$, $3.65 \%$ and $6.19 \%$ ), conversely, it is noted that the mass losses in the case of DEI alone $(0.95 \%, 1.62 \%$ and $2.4 \%)$ are comparable to those of DEHP $(0.83 \%, 1.15 \%$ and $1.93 \%$ ), and they decrease with the incorporation of the ESO into the plasticizer system with the DEI at $(0.11 \%$, $0.27 \%$ and at $0.35 \%$ ) and with the insertion of ESOME at $0.29 \%, 0.32 \%$ and at $0.32 \%$.

This can be explained by the fact that the decrease of the mass loss by volatility in the formulations which contained ESO or ESOME in their plasticizing system, by the reaction of the epoxide function and the $\mathrm{HCl}$ produced by the dehydrochlorination of $\mathrm{PVC}$ and the higher number of ester bonds which could reduce the volatility ${ }^{[31]}$. As for the case of the DEI or the ATBC and even the DEHP, herein, there is no reaction between the plasticizer and $\mathrm{HCl}$, assuming that

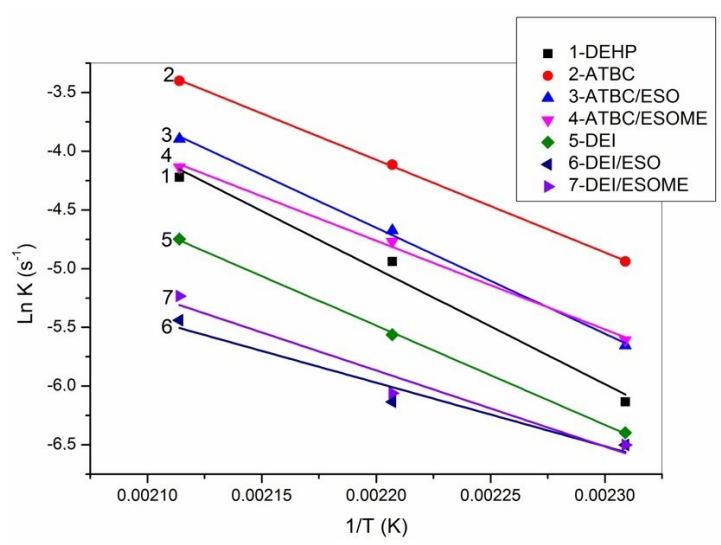

Figure 2. Arrhenius activation energy plots for PVC plasticized by ATBC, DEI and their mixtures with ESO and ESOME and DEHP as reference.

Table 2. Loss weight and maximum rate of degradation by isothermal TGA mode at $160{ }^{\circ} \mathrm{C}, 180{ }^{\circ} \mathrm{C}$ and at $200{ }^{\circ} \mathrm{C}$ and Arrhenius activation energy.

\begin{tabular}{|c|c|c|c|c|c|c|c|c|}
\hline \multirow{2}{*}{\multicolumn{2}{|c|}{$\begin{array}{c}\text { Plasticizer Systems composition } \\
(\%)\end{array}$}} & \multicolumn{2}{|c|}{$160^{\circ} \mathrm{C}$} & \multicolumn{2}{|c|}{$180^{\circ} \mathrm{C}$} & \multicolumn{2}{|c|}{$200^{\circ} \mathrm{C}$} & \multirow{2}{*}{$\begin{array}{c}\text { Activation energy } \\
\text { kJ.mol }^{-1}\end{array}$} \\
\hline & & $\Delta \mathrm{m} / \mathrm{m}_{0}(\%)$ & $\begin{array}{l}V_{\max }(\% / \\
\min )\end{array}$ & $\Delta \mathrm{m} / \mathrm{m}_{0}(\%)$ & $\begin{array}{l}\mathrm{V}_{\max }(\% / \\
\min )\end{array}$ & $\Delta \mathrm{m} / \mathrm{m}_{0}(\%)$ & $\begin{array}{l}V_{\max }(\% / \\
\min )\end{array}$ & \\
\hline DEHP & 100 & 8.70 & 0.13 & 23.56 & 0.43 & 33.19 & 0.88 & $81.79 \pm 9.63$ \\
\hline ATBC & 100 & 21.73 & 0.43 & 30.31 & 0.98 & 36.05 & 2.00 & $65.55 \pm 0.96$ \\
\hline ATBC/ESO & $50 / 50$ & 11.50 & 0.21 & 17.45 & 0.56 & 20.79 & 1.22 & $75.09 \pm 2.97$ \\
\hline ATBC/ESOME & $50 / 50$ & 09.96 & 0.22 & 15.05 & 0.51 & 18.75 & 0.96 & $62.90 \pm 3.44$ \\
\hline DEI & 100 & 4.79 & 0.10 & 12.90 & 0.23 & 25.18 & 0.52 & $70.25 \pm 1.44$ \\
\hline DEI/ESO & $50 / 50$ & 3.02 & 0.09 & 06.64 & 0.13 & 12.92 & 0.26 & $44.97 \pm 9.2$ \\
\hline DEI/ESOME & $50 / 50$ & 3.87 & 0.09 & 7.37 & 0.14 & 14.14 & 0.32 & $53.79 \pm 10.89$ \\
\hline
\end{tabular}

$\mathrm{m}$ : the final mass of the sample; $\mathrm{m}_{0}$ : the initial mass of the sample; $\Delta \mathrm{m}=\left(\mathrm{m}_{0}-\mathrm{m}\right) ; \mathrm{V}_{\max }$ : the maximum degradation rate in $\% / \mathrm{min}$. 
the mass lost by volatilization at high temperatures contains the volatilized plasticizer and $\mathrm{HCl}^{[32,33]}$. The greatest loss of mass in the case of ATBC can be explained by its boiling point $\left(173^{\circ} \mathrm{C}\right)$ which is much lower than that of the DEI $\left(375^{\circ} \mathrm{C}\right)$ and the DEHP $\left(385^{\circ} \mathrm{C}\right)$. Therefore, the use of ESO and ESOME as secondary plasticizers is recommended to reduce the loss of mass by volatility and maintain the mechanical properties of sheets for longer life time.

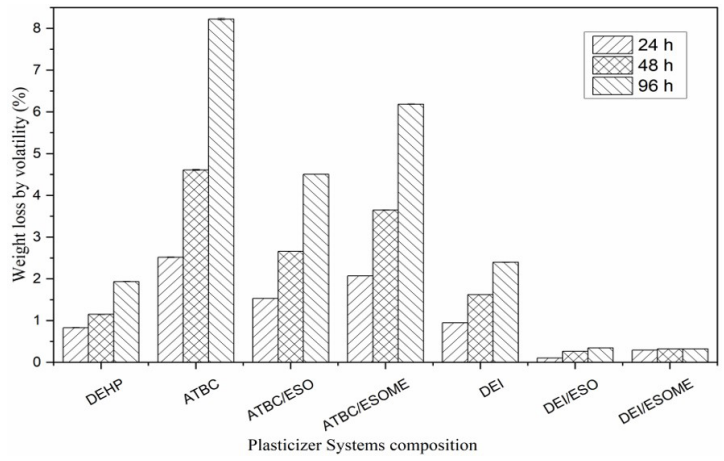

Figure 3. Volatility weight loss of mixtures composed by different combinations of plasticizers at $100{ }^{\circ} \mathrm{C}$ for 24,48 and 96 hours.

(a)

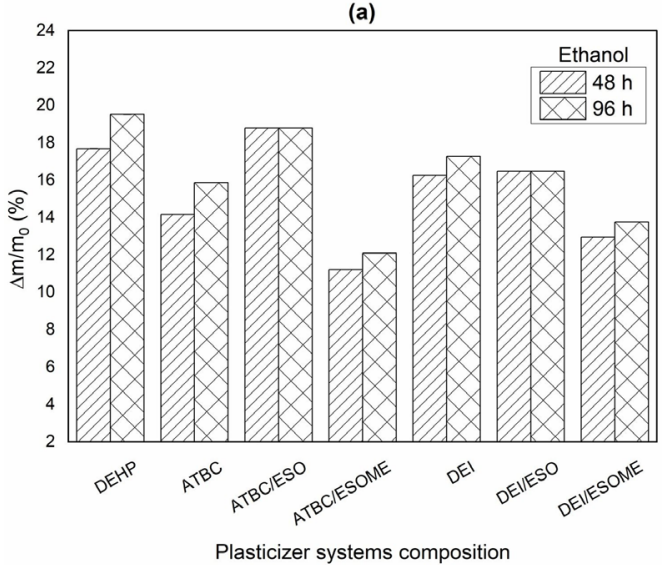

(c)

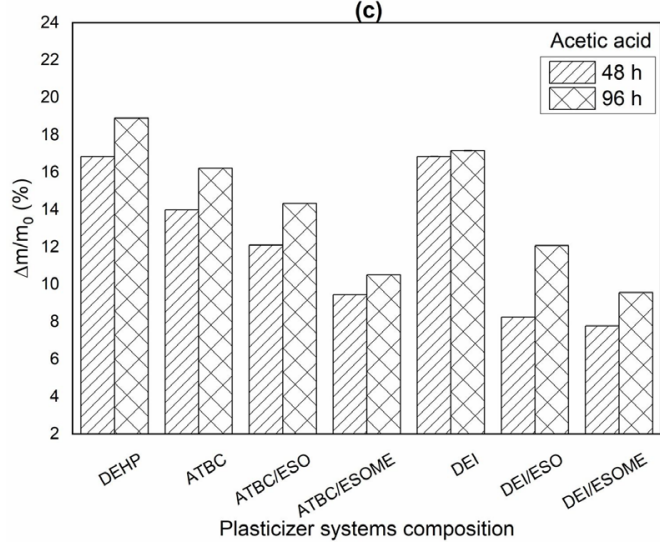

\subsection{Migration test}

The probability of extraction of the plasticizer increases when a polymer material comes into contact with liquids (solvents) ${ }^{[34]}$. The resistance to migration of different plasticizer systems in PVC blends was investigated by the migration test using four different solvents as food simulants.

Figure 4 shows the mass loss by migration in ethanol, petroleum ether, acetic acid and n-heptane from PVC sheets after 48 and 96 hours where each value was the average of three specimens. It is worth noting that the migration rate of all plasticizer systems in all solvents is lower than that of DEHP. Mixtures of plasticizers have lower migration rates as compared to a single plasticizer such as the cases of DEI and ATBC. Hence, the combination of different plasticizers in PVC plasticization reduces the migration. Indeed, the interactions created between the plasticizers prevent their easy migration from the material to its surrounding environment ${ }^{[35]}$ that is to say that the plasticizer that migrates with a slower speed limits the speed of the plasticizer which diffuses faster. The use of plasticizer blends in PVC samples has been shown to reduce migration in comparison to those containing a single plasticizer ${ }^{[28]}$.

It is also found that ESOME has a low migration rate as compared to ESO, the increase in the polarity of ESOME

(b)

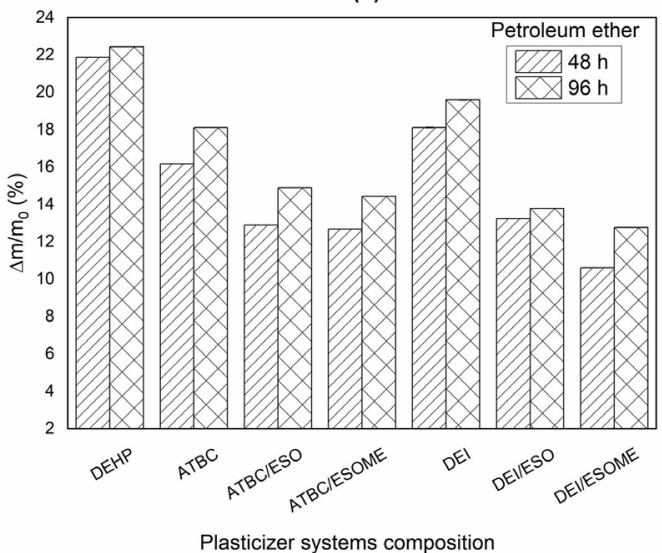

(d)

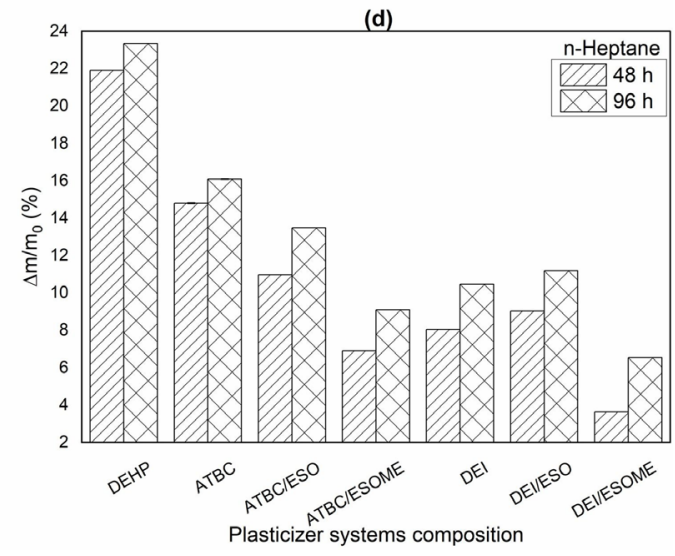

Figure 4. Weight loss by migration in: (a) ethanol; (b) petroleum ether; (c) acetic acid; and (d) n-heptane of the various compositions of the plasticizer systems. 
due to the ester functions which make it possible to create interactions with the PVC (interactions between the function $\mathrm{C}=\mathrm{O}$ and the $\mathrm{C}-\mathrm{Cl}$ bond ${ }^{[36]}$ which is responsible for the reduction of the migration rate. In general, the migration of the plasticizers is influenced by the polarity of the plasticizer and the solvent with which the PVC is in contact ${ }^{[37,38]}$, which affects the compatibility of the plasticizer with PVC, that is to say the plasticizer-PVC interaction forces are greater as compared to those of the plasticizer-solvent, then the migration rate is lower, thus, the excellent solvent resistance of plasticizers retain the PVC properties possibly longer life time ${ }^{[19,39]}$, it is suggested that the migration of plasticizers such as ESBO also depends on the manufacturing process of the PVC films ${ }^{[40]}$.

\subsection{Plastograph test}

Figure 5 shows the evolution of the torque as a function of time for the various compositions of the plasticizer system. To be noted is that we find that the curves of formulations containing DEHP, DEI and ATBC have all a similar shape. After the torque goes stable, its value starts to rise again. This is called the onset of degradation ${ }^{[4]}$. Which is mainly caused by the formation of double bonds, which occurs from the dehydrochlorination of $\mathrm{PVC}^{[15]}$, the further increase in the torque curve whose viscosity increases is a result of the crosslinking of chains containing double bonds ${ }^{[2]}$. All samples degrade after 1000 seconds, but with the incorporation

(a)

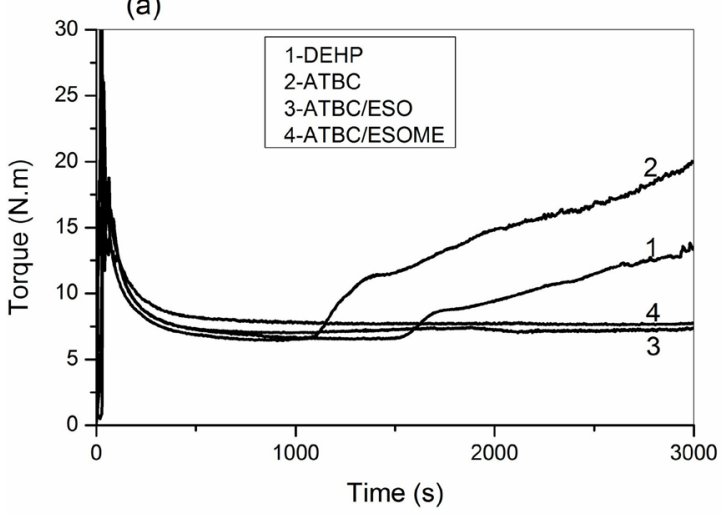

(b)

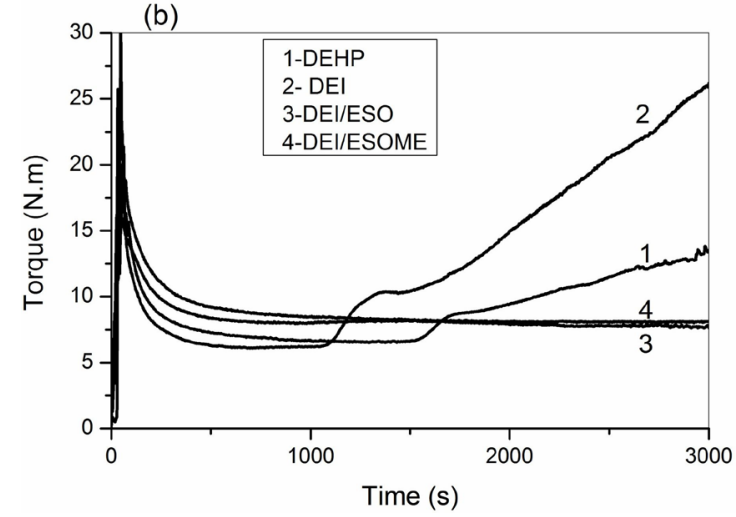

Figure 5. Torque/Time curves for the various compositions of the plasticizer systems (a) in presence of ATBC; (b) in presence of DEI. of ESO or ESOME in the composition of the plasticizer system, the dynamic thermal stability of PVC increases very significantly. Herein, we notice that the degradation time exceeds 2500 seconds.

Table 3 presents the fusion time evolution, the minimum torque and the stability time as a function of the composition of the plasticizer mixture. It is observed that the fusion time of the formulations is minimal in the cases of ATBC and DEI alone, but it increases with the integration of ESO or ESOME in the plasticizer mixtures, where it reaches a maximum point at 436 seconds with $\mathrm{DEI} / \mathrm{ESO}$, this fusion time increase in the case of ESO is explained due to the large number of carbon in triglyceride which reduces somewhat its compatibility with PVC as reported by Garcia and Marcilla $^{[43]}$. All formulations have a lower fusion time than DEHP (482 sec.) indicating a better compatibility of PVC with these plasticizer combinations as compared to DEHP. The same thing happened for the minimum torque which is related to the material melt viscosity ${ }^{[44]}$, which increases with the addition ESO or ESOME in the plasticizer systems. It is explained by the high viscosity of these secondary plasticizers as compared to DEI and ATBC.

Regarding the dynamic thermal stability plateau in torque/ time curves, where the time at which the torque is constant is considered as a stability time ${ }^{[41]}$, we observe that ESO or ESOME increases the stability time once incorporated in the plasticizer systems. This confirms the results of TGA, where the epoxide function reacts with the $\mathrm{HCl}$ released by the PVC dehydrochlorination reaction and limits the autocatalytic role of $\mathrm{HCl}$ in $\mathrm{PVC}$ degradation.

\subsection{Light transmission}

The transmission of light is a study of the diffusion of electromagnetic radiation through plasticized PVC films in a particular region of the spectrum: in the ultraviolet wavelengths (from 200 to $400 \mathrm{~nm}$ ), the visible light (from 400 to $750 \mathrm{~nm}$ ) and the near infrared (from 750 to $1050 \mathrm{~nm}$ ). To do this, we have chosen the transmission almost at half of each range to note the difference between the different formulations, for instance, at $300 \mathrm{~nm}$ for UV, $550 \mathrm{~nm}$ for the visible range and 900 for IR as presented in Table 4 .

PVC is optically a very transparent material, but its transparency could be affected by the addition of additives such as thermal stabilizer ${ }^{[45]}$ or lubricant, which explains the lowering of transparency to than $82 \%$ for all sheets.

In Figure 6, the light transmission of PVC blends was plotted as a function of the composition of the plasticizer system and as a function of wavelength. Note that the transmission curves look alike for all PVC blends/plasticizers. The results show that transmission in the case of DEI $(84.63 \%, 80.65 \%$, and $11.38 \%)$ or ATBC $(84.94 \%, 81.37 \%$ and $17.64 \%)$ is superior to DEHP $(83.92 \%, 79.62 \%$, and $2.78 \%$ ) for the infrared, visible and ultraviolet ranges, while the incorporation of ESO or ESOME is observed to decrease the light transmission. This reduction in light transmission is probably due to the type of plasticizer system composition used in the sheet formulation, probably because of the epoxy group, or the length of the secondary plasticizer chain ${ }^{[46]}$. 
Table 3. Fusion rheological characteristics of PVC formulations plasticized with various compositions of plasticizer systems

\begin{tabular}{ccccc}
\hline \multicolumn{2}{c}{ Plasticizer systems composition (\%) } & Fusion time (s) & Minimum torque (Nm) & Stability time (s) \\
\hline DEHP & 100 & 482 & 6.8 & 1078 \\
ATBC & 100 & 354 & 6.6 & 738 \\
ATBC/ESO & $50 / 50$ & 414 & 7.1 & $>2586$ \\
ATBC/ESOME & $50 / 50$ & 368 & 7.7 & $>2632$ \\
DEI & 100 & 372 & 6.3 & 712 \\
DEI/ESO & $50 / 50$ & 436 & 8.1 & $>2564$ \\
DEI/ESOME & $50 / 50$ & 404 & 8.2 & 2694 \\
\hline
\end{tabular}

Table 4. Light transmission in PVC sheets.

\begin{tabular}{ccccc}
\hline \multicolumn{2}{c}{ Plasticizer systems composition (\%) } & \multicolumn{3}{c}{ Transmission (\%) } \\
\cline { 3 - 5 } & UV (300nm) & & Visible $\mathbf{( 5 5 0} \mathbf{~ n m})$ & IR (900 nm) \\
\hline DEHP & 100 & 2.78 & 79.62 & 83.92 \\
ATBC & 100 & 17.64 & 81.37 & 84.94 \\
ATBC/ESO & $50 / 50$ & 4.08 & 68.96 & 79.72 \\
ATBC/ESOME & $50 / 50$ & 1.08 & 69.19 & 79.74 \\
DEI & 100 & 11.38 & 80.65 & 84.63 \\
DEI/ESO & $50 / 50$ & 3.57 & 73.91 & 82.92 \\
DEI/ESOME & $50 / 50$ & 1.28 & 68.77 & 83.28 \\
\hline
\end{tabular}

(a)

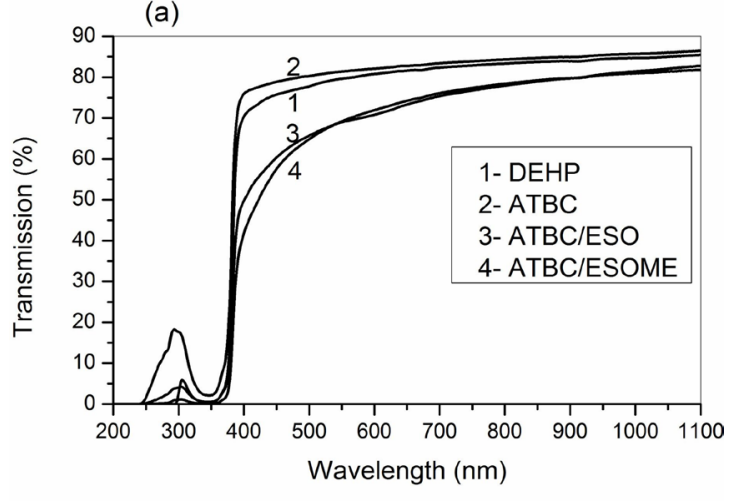

(b)

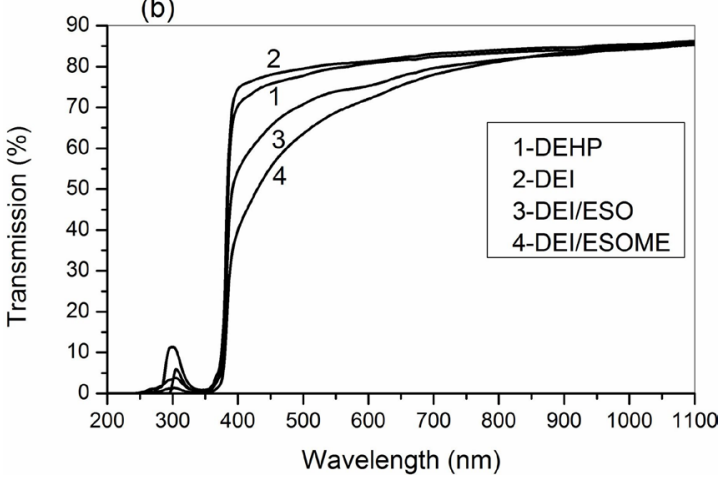

Figure 6. Light transmission variation of different compositions of PVC films (a) in presence of ATBC; (b) in presence of DEI, as a function of wavelength.

All samples show a sharp decrease in transmission at $380 \mathrm{~nm}$ but a transmission band of about $280 \mathrm{~nm}$ is observed for all formulations. This significant increase in transmission below $300 \mathrm{~nm}$ is associated with the $\mathrm{C}-\mathrm{Cl}$ bond of $\mathrm{PVC}^{[47]}$.

\section{Conclusions}

According to thermogravimetric analysis, formulations which contain DEHP, DEI and ATBC have maximum weight losses, because those are primary plasticizers and do not have a good thermal satability. Therefore, the incorporation of secondary plasticizers either ESO or ESOME into the plasticizer system improves significatively the thermal stability of PVC blends.

The decrease in mass loss by volatility in formulations containing ESO or ESOME in their plasticizer system can be explained by the reaction of the epoxide function and the $\mathrm{HCl}$ produced by the dehydrochlorination of PVC. The combination of different plasticizers in PVC plasticization reduces migration. Indeed, the interactions created between plasticizers prevent migration. It is also found that the ESOME has a low migration rate compared to the ESO, the increase in the polarity of the ESOME due to the ester functions which makes it possible to create interactions with PVC, in general, the migration of the plasticizers is influenced by the polarity of the plasticizer and the solvent with which the PVC is in contact, which influences the compatibility of the plasticizer with the PVC. The results of the internal mixer show that the thermal stability improves with the increase of the rate of ESO or ESOME. This confirms the results of TGA, where the epoxide function reacts with the $\mathrm{HCl}$ released by the PVC dehydrochlorination reaction and limits the autocatalytic role of $\mathrm{HCl}$ in PVC degradation. The light transmission test shows that the incorporation of the ESO or the ESOME leads to a difference in transparency, where the transmission of light decreased with the increase of the rate of the latter in the plasticizer system.

As purpose of this study was to provide alternatives to phthalates by the use of epoxidized sunflower oil and the methyl ester of epoxidized sunflower oil as secondary plasticizers, mixed with two primary bio sourced plasticizers such as di-esters Isosorbide (DEI) and acetyl tributyl citrate 
(ATBC), to plasticize PVC and seek to obtain properties similar or even better than those of di-(2-ethylhexyl) phthalate, then the mixtures of ESO and ESOME with DEI and with ATBC derived from renewable resources, show plasticization efficiency and can be applied as alternative plasticizers for conventional plasticizers based on a fossil source.

\section{Acknowledgements}

The authors would gratefully like to acknowledge the financial support of General Directorate for Scientific Research and Technological Development (DGRSDT), Algeria, for their support in this work.

\section{References}

1. Demir, A. P. T., \& Ulutan, S. (2013). Migration of phthalate and non-phthalate plasticizers out of plasticized PVC films into air. Journal of Applied Polymer Science, 128(3), 1948-1961. http://dx.doi.org/10.1002/app.38291.

2. Saeki, Y., \& Emura, T. (2002). Technical progresses for PVC production. Progress in Polymer Science, 27(10), 2055-2131. http://dx.doi.org/10.1016/S0079-6700(02)00039-4.

3. Daniels, P. H. (2009). A brief overview of theories of PVC plasticization and methods used to evaluate PVC-plasticizer interaction. Journal of Vinyl and Additive Technology, 15(4), 219-223. http://dx.doi.org/10.1002/vnl.20211.

4. Marcilla, A., García, S., \& Garcia-Quesada, J. C. (2008). Migrability of PVC plasticizers. Polymer Testing, 27(2), 221233. http://dx.doi.org/10.1016/j.polymertesting.2007.10.007.

5. Chen, J., Liu, Z., Li, K., Huang, J., Nie, X., \& Zhou, Y. (2015). Synthesis and application of a natural plasticizer based on cardanol for poly (vinyl chloride). Journal of Applied Polymer Science, 132(35), 42465-42474. http://dx.doi.org/10.1002/ app. 42465 .

6. Murphy, J. (2001). Additives for plastics handbook. New York: Elsevier Science. http://dx.doi.org/10.1016/B978-1-85617370-4.X5000-3.

7. Ren, Y., Wu, G., Zhao, X., Liu, X., \& Liu, F. (2010). Effect of poly (epichlorohydrin) on the thermal and mechanical properties of poly (vinyl chloride). Journal of Applied Polymer Science, 118(6), 3416-3424. http://dx.doi.org/10.1002/app.32687.

8. Rhee, G. S., Kim, S. H., Kim, S. S., Sohn, K. H., Kwack, S. J., Kim, B. H., \& Park, K. L. (2002). Comparison of embryotoxicity of ESBO and phthalate esters using an in vitro battery system. Toxicology In Vitro, 16(4), 443-448. http://dx.doi.org/10.1016/ S0887-2333(02)00026-7. PMid:12110284.

9. Jia, P., Bo, C., Hu, L., Zhang, M., \& Zhou, Y. (2016). Synthesis of a novel polyester plasticizer based on glyceryl monooleate and its application in poly (vinyl chloride). Journal of Vinyl and Additive Technology, 22(4), 514-519. http://dx.doi.org/10.1002/ vnl.21468.

10. Jia, P., Zhang, M., Hu, L., Feng, G., Bo, C., \& Zhou, Y. (2015). Synthesis and application of environmental castor oil based polyol ester plasticizers for poly (vinyl chloride). ACS Sustainable Chemistry \& Engineering, 3(9), 2187-2193. http://dx.doi.org/10.1021/acssuschemeng.5b00449.

11. Mohammed, F. S., Conley, M., Saunders, S. R., Switzer, J., Jha, R., Cogen, J. M., Chaudhary, B. I., Pollet, P., Eckert, C. A., \& Liotta, C. L. (2015). Epoxidized linolenic acid salts as multifunctional additives for the thermal stability of plasticized PVC. Journal of Applied Polymer Science, 132(13), 41736. http://dx.doi.org/10.1002/app.41736.

12. Nguyen, T. D., Nguyen, C. T., Tran, V. T. T., Nguyen, G. V., Le, H. V., Tran, L. D., Bach, G. L., \& Thai, H. (2018).
Enhancement of the thermomechanical properties of a fly ash-and carbon black-filled polyvinyl chloride composite by using epoxidized soybean oil as a secondary bioplasticizer. International Journal of Polymer Science, 8428736, 1-8. http:// dx.doi.org/10.1155/2018/8428736.

13. Jia, P., Xia, H., Tang, K., \& Zhou, Y. (2018). Plasticizers derived from biomass resources: a short review. Polymers, 10(12), 1303. http://dx.doi.org/10.3390/polym10121303. PMid:30961228.

14. Sampson, J., \& Korte, D. (2011). DEHP-plasticised PVC: relevance to blood services. Transfusion Medicine, 21(2), 73-83. http://dx.doi.org/10.1111/j.1365-3148.2010.01056.x. PMid:21143327.

15. Bouchoul, B., Benaniba, M. T., \& Massardier, V. (2014). Effect of biobased plasticizers on thermal, mechanical and permanence properties of poly (vinyl chloride). Journal of Vinyl and Additive Technology, 20(4), 260-267. http://dx.doi. org/10.1002/vnl.21356.

16. Jia, P., Zhang, M., Hu, L., \& Zhou, Y. (2016). Green plasticizers derived from soybean oil for poly (vinyl chloride) as a renewable resource material. Korean Journal of Chemical Engineering, 33(3), 1080-1087. http://dx.doi.org/10.1007/s11814-015-02139.

17. Bouchoul, B., Benaniba, M. T., \& Massardier, V. (2017). Thermal and mechanical properties of bio-based plasticizers mixtures on poly (vinyl chloride). Polímeros: Ciência e Tecnologia, 27(3), 237-246. http://dx.doi.org/10.1590/0104-1428.14216.

18. Gil, N., Saska, M., \& Negulescu, I. (2006). Evaluation of the effects of biobased plasticizers on the thermal and mechanical properties of poly (vinyl chloride). Journal of Applied Polymer Science, 102(2), 1366-1373. http://dx.doi.org/10.1002/app.24132.

19. Jia, P., Ma, Y., Zhang, M., Hu, L., \& Zhou, Y. (2019). Designing rosin-based plasticizers: effect of differently branched chains on plasticization performance and solvent resistance of flexible poly (vinyl chloride) films. ACS Omega, 4(2), 3178-3187. http://dx.doi.org/10.1021/acsomega.8b03612. PMid:31459535.

20. Qadros, J. V. D., Jr., \& Carvalho, J. A. (2008). EP2070977. Germany: EPO. Retrieved in 2021, February 3, from https:// data.epo.org/publication-server/document?iDocId $=3445287$ \&iFormat $=2$

21. Quadros, J. V. D., Jr. (2015). Estudo da reação de epoxidação do óleo de soja em condição de remoção de calor máxima (Doctoral dissertation). Universidade de São Paulo, São Paulo.

22. Luo, X., Chu, H., \& Liu, M. (2020). Synthesis of bio-plasticizer from soybean oil and its application in poly (vinylchloride) films. Journal of Renewable Materials, 8(10), 1295-1304. Retrieved in 2021, February 3, from https://www.techscience. $\mathrm{com} / \mathrm{jrm} / \mathrm{v} 8 \mathrm{n} 10 / 40075 / \mathrm{pdf}$

23. Bouchareb, B., \& Benaniba, M. T. (2008). Effects of epoxidized sunflower oil on the mechanical and dynamical analysis of the plasticized poly (vinyl chloride). Journal of Applied Polymer Science, 107(6), 3442-3450. http://dx.doi.org/10.1002/app.27458.

24. Hinault, R., \& Barbier, J. (2012). US Patent No 8093319 B2. Washington: U.S. Patent and Trademark Office. Retrieved in 2021, February 3, from https://patents.google.com/patent/ US8093319B2/en

25. American Society for Testing and Materials-ASTM. (2014). ASTM D1239-14: standard test method for resistance of plastic films to extraction by chemicals. Pennsylvania: ASTM.

26. Ou, Y., Ding, X., \& Zhang, L. (2014). Synthesis and application of an alternative plasticizer Di (2-Ethylhexyl)-1, 2-cyclohexane dicarboxylate. Journal of Applied Polymer Science, 131(2), n/a. http://dx.doi.org/10.1002/app.39763.

27. Lee, S., Park, M. S., Shin, J., \& Kim, Y.-W. (2018). Effect of the individual and combined use of cardanol-based plasticizers and epoxidized soybean oil on the properties of PVC. Polymer 
Degradation \& Stability, 147, 1-11. http://dx.doi.org/10.1016/j. polymdegradstab.2017.11.002.

28. Brouillet, S., \& Fugit, J.-L. (2009). Solutions to reduce release behavior of plasticizers out of PVC-made equipments: binary blends of plasticizers and thermal treatment. Polymer Bulletin, 62(6), 843-854. http://dx.doi.org/10.1007/s00289-009-0055-x.

29. Chen, J., Li, X., Wang, Y., Li, K., Huang, J., Jiang, J., \& Nie, X. (2016). Synthesis and application of a novel environmental plasticizer based on cardanol for poly (vinyl chloride). Journal of the Taiwan Institute of Chemical Engineers, 65, 488-497. http://dx.doi.org/10.1016/j.jtice.2016.05.025.

30. Gao, C., Wang, B., Hu, Z., Liu, Y., Wang, H., Zhang, X., \& Wu, Y. (2019). Effect of the molecular weight on the plasticization properties of poly (hexane succinate) in poly (vinyl chloride) blends. Journal of Applied Polymer Science, 136(8), 47081. http://dx.doi.org/10.1002/app.47081

31. Feng, G., Hu, L., Ma, Y., Jia, P., Hu, Y., Zhang, M., Liu, C., \& Zhou, Y. (2018). An efficient bio-based plasticizer for poly (vinyl chloride) from waste cooking oil and citric acid: synthesis and evaluation in PVC films. Journal of Cleaner Production, 189, 334-343. http://dx.doi.org/10.1016/j.jclepro.2018.04.085.

32. Yang, Y., Huang, J., Zhang, R., \& Zhu, J. (2017). Designing bio-based plasticizers: effect of alkyl chain length on plasticization properties of isosorbide diesters in PVC blends. Materials \& Design, 126, 29-36. http://dx.doi.org/10.1016/j. matdes.2017.04.005.

33. Bouchoul, B., \& Benaniba, M. T. (2016). Poly (chlorure de vinyle) (PVC) plastifié par des mélanges des plastifiants d'origine biosourcés: synthèse et caractérisation. Journal of Materials, Processes and Environment, 4(2), 77-80. Retrieved in 2021, February 3, from https://www.asjp.cerist.dz/en/article/15623

34. Faria-Machado, A. F., Silva, M. A., Vieira, M. G. A., \& Beppu, M. M. (2013). Epoxidation of modified natural plasticizer obtained from rice fatty acids and application on polyvinyl chloride films. Journal of Applied Polymer Science, 127(5), 3543-3549. http://dx.doi.org/10.1002/app.37671.

35. Boussoum, M. O. (2012). Etude de méthodes de traitement pour diminuer la migration à partir des emballages en PVC (Doctoral dissertation). Ecole Nationale Supérieure Polytechnique, Algeria.

36. Howick, C. (1995). Studies of molecular interactions between PVC and plasticisers. Plastics, Rubber and Composites Processing and Applications, 23(1), 53-60. Retrieved in 2021, February 3, from https://www.infona.pl/resource/bwmeta1. element.elsevier-429efeda-2464-3b44-824a-a5426aa55e2

37. Silva, C. F., Oliveira, F. S. M., Caetano, V. F., Vinhas, G. M., \& Cardoso, S. A. (2018). Orange essential oil as antimicrobial additives in poly (vinyl chloride) films. Polímeros: Ciência e Tecnologia, 28(4), 332-338. http://dx.doi.org/10.1590/01041428.16216 .
38. Bhunia, K., Sablani, S. S., Tang, J., \& Rasco, B. (2013). Migration of chemical compounds from packaging polymers during microwave, conventional heat treatment, and storage. Comprehensive Reviews in Food Science and Food Safety, 12(5), 523-545. http://dx.doi.org/10.1111/1541-4337.12028. PMid:33412668.

39. Jia, P., Ma, Y., Xia, H., Zheng, M., Feng, G., Hu, L., Zhang, M., \& Zhou, Y. (2018). Clean synthesis of epoxidized tung oil derivatives via phase transfer catalyst and thiol-ene reaction: a detailed study. ACS Sustainable Chemistry \& Engineering, 6(11), 13983-13994. http://dx.doi.org/10.1021/ acssuschemeng.8b02446.

40. Choi, M. S., Rehman, S. U., Kim, H., Han, S. B., Lee, J., Hong, J., \& Yoo, H. H. (2018). Migration of epoxidized soybean oil from polyvinyl chloride /polyvinylidene chloride food packaging wraps into food simulants. Environmental Science and Pollution Research International, 25(5), 5033-5039. http:// dx.doi.org/10.1007/s11356-017-0951-9. PMid:29273993.

41. Bijhanmanesh, M. J., Etesami, N., \& Darvishi, R. (2017). Continuous dosing of fast initiator during vinyl chloride suspension polymerization: thermal stability of PVC resin. Journal of Applied Polymer Science, 134(7), 44480. http:// dx.doi.org/10.1002/app.44480.

42. Schramm, G. (1994). A practical approach to rheology and rheometry. Germany: Haake.

43. Garcia, J. C., \& Marcilla, A. (1998). Rheological study of the influence of the plasticizer concentration in the gelation and fusion processes of PVC plastisols. Polymer, 39(15), 35073514. http://dx.doi.org/10.1016/S0032-3861(97)10033-7.

44. Li, X., Nie, X., Chen, J., \& Wang, Y. (2017). Preparation of epoxidized cardanol butyl ether as a novel renewable plasticizer and its application for poly (vinyl chloride). Polymer International, 66(3), 443-449. http://dx.doi.org/10.1002/pi.5280.

45. Wu, B., Wang, Y., Chen, S., Wang, M., Ma, M., Shi, Y., \& Wang, X. (2018). Bis-uracil based high efficient heat stabilizers used in super transparent soft poly (vinyl chloride). Polymer Degradation \& Stability, 149, 143-151. http://dx.doi. org/10.1016/j.polymdegradstab.2018.01.029.

46. Coltro, L., Pitta, J. B., \& Madaleno, E. (2013). Performance evaluation of new plasticizers for stretch PVC films. Polymer Testing, 32(2), 272-278. http://dx.doi.org/10.1016/j. polymertesting.2012.11.009.

47. El Sayed, A. M., El-Sayed, S., Morsi, W. M., Mahrous, S., \& Hassen, A. (2014). Synthesis, characterization, optical, and dielectric properties of poly (vinyl chloride)/cadmium oxide nanocomposites films. Polymer Composites, 35(9), 1842-1851. http://dx.doi.org/10.1002/pc.22839.

Received: Feb. 03, 2021

Revised: Aug. 31, 2021

Accepted: Sept. 16, 2021 